\title{
Gender Differences and the Effects of Sibling Composition on Parents' Educational Expectations: Findings from a Case of China
}

Yun Jiang

Nanjing Normal University, China

\section{ARTICLE INFO}

Keywords:

Asia

Education

Family background

Reversed gender gap

Social class

\begin{abstract}
This research aims to examine gender differences in parents' expectations for the education of their children in China. With rich information from the 2013/14 wave of China Education Panel Survey Data, this study used the ordinary least squares regression with the statistical package STATA to examine the effects of teenager gender, the number of siblings and sibling sex composition on parents' educational expectations in China. Different from previous studies in China, this study found that parents have higher educational expectations for girls than for boys, and the higher rate of return to education for girls might be one of the explanations for this phenomenon. Additionally, residential areas, parents' educational levels, and father's occupational status show a significant impact on narrowing the gender gap in parents' educational expectations. This study also focuses on the sibling composition in the family, which includes the number of siblings and the sibling sex composition. Consistent with the dilution model, a larger number of siblings has a negative impact on parents' educational expectations, but this impact has no gender differences. Besides, due to the previous family planning policy, a large number of Chinese families only have one child. This study found that in both one-child families and multiplechildren families, parents still have higher educational expectations for girls, and even in multiple-children families this preference for girls to receive more education is more significant. Different as expected, sibling sex composition does not show any statistically significant influence on parents' educational expectations.
\end{abstract}

\section{Introduction}

Although the traditional 'son preference' is still true in some areas of China, Chinese government has paid much effort to narrow the gender difference, especially since the economic reform and the opening-up policy in the late 1970s. Special thanks should give to the expansion of education opportunities (Lavely et al., 1990; Liu \& Wang, 2008), such as the policy to increase enrolment in higher education adopted by the Chinese government during 1999-2002 $(\mathrm{Li}, 2010)$, that enable girls to control their own life, rather than get prepared to get married and take care of the new family. Another key policy that reduces the gender inequality in China is the one-child policy introduced in 1980 s, that is, 'one family can only have one child' and 'rural families can have a second child if the first child was a girl' (Scharping, 2003). Due to the 'onechild' policy, the birth rate in China has dropped dramatically. The scale of most families has been downsized, and the educational resources thus can be concentrated to the 'only' child in the family, especially giving more educational opportunities to girls, who could have stopped their studies early to spare educational resources for other siblings in the family (Ye \& $\mathrm{Wu}$,

* Corresponding Author E-Mail Address: yun_jiang0527@163.com 
2011; Wang, 2011). The number of girls has started to outnumber boys in terms of the entrance to universities in recent years, and some scholars called it as the 'reversed gender gap' $(\mathrm{Li}$, 2010; Ye \& Wu, 2011).

At the macro level, China's social progress has already made great achievements to balance gender inequality in education, but at the micro level, we may still need to examine the familyrelated factors, which may also be a key influencing the gender difference. It should not be ignored that the configuration of family may change and once again affect the distribution of education resources in the family. That is, with the reality of low birth rate and aging society, China has implemented the two-child policy in 2016 that allows all families to have a maximum of two children, and this policy might constrain girls' advantage in educational attainment brought by the one-child policy. In fact, while the general tendency towards gender equality in education is positive, girls still receive less education when their families are in lower socioeconomic position, live in rural areas, or have more siblings ( $\mathrm{Li}, 2009 ; \mathrm{Wu}, 2012$ ) Moreover, the sibling sex composition, which means whether having any brother or any sister and the percentage of girls, shows different impacts on boys' and girls' educational attainment (Zheng, 2013). Given this, parents' expectation for their children's education attainment and children's actual education attainment would be different now and in the future, compared with a couple of decades ago.

In this regard, the empirical research has shown us some evidence. Generally, research reported that Chinese parents hoped boys to obtain more education than girls (Liu et al., 2014; Xu \& Zhou, 2017; Cui \& Song, 2019). Cui and Song (2019) found that parents would more like girls to receive undergraduate education than boys, but after finishing the undergraduate education, parents prefer boys to girls to complete postgraduate studies. However, when examining the factors that contribute to this phenomenon, some findings in the literature seem not consistent. Some scholars have attempted to examine the relationship between parent's expectations on their children's education and the family size. On the one hand, Liu (2014) found that girls in the one-child families were expected to receive more education, but when the family had more than one child, restricted by the limited educational resources, parents were more likely to reduce expectations for girls rather than for boys. On the other hand, the research finding from Cui and Song (2019) showed that parents expect their boys to have more educational years than girls in the one-child families.

Since only by examining the number of siblings is not enough to interpret the casualrelationship between gender difference and parents' expectation on children's education, the attention has also turned to explore the effect of the sibling sex composition on the educational attainment. That is, whether or not girls who have brother(s) are more disadvantageous in obtaining educational resources than those who only have sister(s) (Powell \& Steelman, 1989; 1990; Kaestner, 1997; Hauser \& Kuo, 1998; Jacob, 2011; Zheng, 2013). Powell and Steelman $(1989 ; 1990)$ showed that having brothers has a more negative impact on educational attainment than having only sisters for girls, because they found that boys received less financial support from their parents than girls. Further, Jacob (2011) showed that women having older brothers are less likely to graduate from tertiary education than those who only have older sisters, and Jacob explained that this might be because the families take sequent decisions and do not plan to offer education to all children. There are also studies which show no effect of sibling sex composition at all (Kaestner, 1997; Hauser \& Kuo, 1998). With just a few studies analysing the effect of sibling sex composition on children's education in China, to my knowledge, only Zheng (2013) found that having brothers is negative to girls' educational attainment, but brings no significant effects on boy's education.

Lastly, another focus on the gender difference in the education is the 'hukou', which means the registered permanent residence in China and usually indicates living in rural or urban areas $(\mathrm{Li}$, 2009; Hannum et al., 2009; $\mathrm{Wu}, 2012$ ). A large body of literature showed that the gender 
inequality in rural areas was more severe than urban areas in China ( $\mathrm{Li} \& \mathrm{Tsang}, 2003$; $\mathrm{Li}$, 2009; Hannum et al., 2009; Wu, 2012). The studies of Li (2009) and Wu (2012) showed that both boys and girls living in rural areas in China receive less education than their counterparts living in urban areas because of the fewer educational resources in rural areas than urban areas, but the negative effect on educational attainment of living in rural areas is larger for girls than boys. Hannum (2009) found that in Gansu province in China, although mothers in the countryside of Gansu thought that education is as important for girls as for boys, they still hoped their boys to have more education compared with their girls, and when mothers needed help in household chores, they were more used to calling their daughters rather than sons to help. Talking about hukou, another closely related factor is the household's socioeconomic background. Most studies agreed that girls coming from the well-off background and whose parents have a higher occupational status have completed a higher degree of education than their counterparts coming from lower socioeconomic families (Hannum, 2005; Li, 2009; Wu, 2012). Existing research also showed that girls whose parents receive more education are more likely to have a higher level of educational attainment than those whose parents' educational background is lower both in the United States (Buchmann \& DiPrete, 2006) and China (Li, 2009; $\mathrm{Wu}, 2012$ ).

Given the above discussion, it can be seen that while the literature has already presented some knowledge on parent's expectations on children's education and the actual educational attainment of their children, there exist at least three gaps that need to be filled. First, most research only focused on a certain region, but it is worthy to consider whether or not the results may be different if taking the whole China into account. This point is very important, mainly because the contrary results mentioned in former paragraphs might lie in the different data that they used. Second, most studies explored the effect of family size, the 'hukou', and the family socioeconomic background on the general parents' educational expectations but do not focus on the interactive effects of gender and these effects (Liu et al., 2014; Xu \& Zhou, 2017; Cui \& Song, 2019). Third, previous studies examined the effect of sibling sex composition only on children's educational attainment, while this study will examine the effect of sibling sex composition on parents' educational expectations for their children.

Therefore, due to these gaps, this research aims to examine gender differences in parents' expectations for the education of their children in China. More specifically, this research hopes provide three distinctive angles in the study of parents' expectation for children's education attainment and gender differences. Firstly, the test of gender differences in parents' educational expectations for their children is done on a nationwide scale with the latest national data of China Education Panel Survey (CEPS). Secondly, the interactive effects of gender with the family sizes, the 'hukou', and the family socioeconomic backgrounds (the household incomes, the type of employment of children's father and parents' educational levels) on parents' educational expectations is tested. Thirdly, the effect of sibling sex composition on parents' educational expectations is tested too. The paper is outlined as following. Section 2 will present the theoretical framework and research hypotheses, followed by the research method and data (Section 3). Section 4 is the findings of this research, and Section 5 will discuss these results.

\section{Theoretical Framework and Hypotheses}

\subsection{Economic Returns of Educational Investment}

Parents would estimate the potential economic return on the education of their children (more specifically, the future income from the labour market), and they tend to invest financially and emotionally in the education of children who have the largest potential to bring back the maximum return of education (Becker \& Tomes, 1979). The Research on Gender Differences in China's Job Market in 2019 (Boss Zhipin) shows that women's salary in China is only equal 
to $78.3 \%$ of men's salary. ${ }^{1}$ Additionally, the Glass Ceiling Theory (Laslett, 1991) indicates that compared to men, women are more likely to encounter invisible barriers to prevent them from upward career. Moreover, in traditional Chinese families, it is usually the sons' responsibility to take care of the old parents (Wu, 2012; Zheng, 2013), and thus in this situation parents are willing to invest more in sons' education to ensure that they will be capable enough to attend them when they are old. Based on this theory, parents might expect their sons, instead of their daughters, to obtain more education. This is because the men are more likely to have a higher income in the labour market, thus bringing more financial returns to the family. Based on the discussion above, the first hypothesis is formed:

H1: In general, parents expect boys to receive more education than girls.

This study considers that the aforementioned explanation of the higher economic returns of boys is often used to explain parents' higher educational expectations in multiple-children families, but in China there exist substantially the 'one-child families' as a result of the compulsory one-child policy. Still based on the logic that parents will consider the economic returns of the children, this study tries to offer a new explanation of parents' educational expectations in one-child families in China. In the one-child families, parents might invest more in girls' education in contrast with boys because of girls' higher ratio of return of educational investment. The literature tells us that in a male-dominated working environment where men are better paid, girls' parents realize that education is one of the opportunities for women to overcome the structural gender inequality in employment, while men do not actively seize the educational opportunities exactly because male employees are traditionally preferred to female employees by most employers (Buchmann et al., 2008; Legewie \& DiPrete, 2009; Quenzel \& Hurrelmann, 2013). Therefore, if a girl is the only child in the family, parents might have more educational expectations for her than the male counterpart. The first reason might be that parents have no alternative male child to invest in. Second, it could be attributed to the fact that more educational investment in the girl might well guarantee her better economic returns in the future labour market. Therefore, this study has the following hypothesis:

H2: In the one-child families, parents expect girls to receive more education than their male counterparts, and in the multiple-children families, parents expect boys to receive more education than girls.

\subsection{Preference for Boys in Rural China}

As mentioned in the beginning of this paper, Chinese traditional culture still has influence on many rural Chinese families to give priority to boys (Li \& Lavely, 2003; Wu, 2012; Zheng, 2013). And under the patriarchal ideas, many rural Chinese families insist to the traditional gender role of 'men are in charge outside and women inside' (nan zhu wai, nu zhu nei 男主 外, 女主内) (Ji, 2017). In other words, men are the breadwinner, while women take care of the family and do housework. Accordingly, some mothers think it unimportant for girls to receive much education because the future role for a girl is a wife, whose primary job is housework, which does not require an advanced level of education (Li \& Tsang, 2003; Wu, 2012). One extreme case from the ancient Chinese society can imply the stereotyping of female role in family and the unnecessity of girls receiving education: 'Ignorance is a woman's virtue' (nu zi wu cai bian shi de 女子无才便是德). Based on the information above, another hypothesis is given:

H3: Compared to parents in urban areas, parents in rural areas expect boys to receive more education than girls.

\footnotetext{
${ }^{1}$ The data are from Research on Gender Differences in China's Job Market, a report written by the research center and the career science lab of Boss Zhipin, one of the largest career consulting companies in China.
} 


\subsection{Dilution Model and Sibling Sex Composition}

The 'dilution model' of Blake (1981) shows that the number of siblings has a negative impact on children's entrance into college. In other words, the more siblings one has, the more possible that one receives less educational support from their parents. This is because with limited educational resources, parents struggle to allocate the limited resources to more children. Therefore, having siblings might be in the first place a negative factor for children to obtain more educational resources in the family. In the second place, out of parents' consideration about the different economic returns of education brought by sons and daughters, and out of some parents' traditional cultural preference for boys, girls might be more vulnerable than boys to be affected negatively by a larger number of siblings. Therefore, this article forms the fourth and fifth hypothesis on the effect of family size and sibling sex composition separately:

H4: The larger family size is negative for children to receive more educational expectations from parents, and this negative impact is stronger on girls than boys.

H5: Having brothers is negative for children to receive more educational expectations from parents, and having sisters or a larger percentage of girls is helpful for children to receive more parents' educational expectations.

\subsection{Effect of Family Socioeconomic Backgrounds}

This study chooses three indicators to measure the family socioeconomic backgrounds: the household incomes, parents' educational levels and the type of employment of children's father. The reasons why the three indicators are selected are explained respectively as follows. First, in terms of the household incomes, when the household incomes are higher, the parents will have more financial resources to allocate in order to offer more education to their children. In such situation, parents might also have higher educational expectations for their daughters, who might have stopped their education earlier out of the limited educational resources. Therefore, the sixth hypothesis is given:

H5: Gender differences in parents' educational expectations vary with different household incomes.

Second, regarding parents' educational levels, Wu indicated that (2012) there exists an evident effect of modern education on attenuating traditional gender ideology that men are superior than women. Also, other studies showed that higher levels of education lead people to have a more egalitarian concept of gender role. This means that parents will not make discriminatory decisions on girls' education (Cherlin \& Walters, 1981; Thornton et al., 1983). Therefore, another hypothesis is developed:

H6: Gender differences in parents' educational expectations vary with different educational levels of parents.

Third, Wu (2012) and Yang (2006) both indicated that fathers who have a higher socioeconomic job show more acceptance towards gender equality in education, and Yang (2006) suggested that it might be because these fathers obtained a higher level of education before obtaining an occupation of higher socioeconomic levels, and as explained before, parents with higher educational levels tend to have a more egalitarian concept of gender role. To examine whether their suggestion is true, this study forms the seventh hypothesis:

H7: Gender differences in parents' educational expectations vary with different types of the father's employment.

\section{Method}

\subsection{Data sources}

This study is grounded on the 2013-2014 data of China Education Panel Survey (CEPS). This survey was designed and implemented by the Chinese General Social Survey (CGSS) of 
Renmin University of China, conducted with the 7th grade and the 9th grade as survey objects, which are national representative samples.

The data of students and parents are merged, and the samples are dropped if the gender, family socioeconomic status, the number of siblings, parents' comments on academic performance and the educational expectations are missing. For the rest of the sample, the missing value of the ethnic group is replaced by 'Han', the major ethnic group in China, the missing value of the highest educational years of parents is replaced by its mean, and that of mother replaces the missing value of the professional status of the father. The sample includes 17216 students from 112 schools in 28 counties in China, based on stratified random sampling.

\subsection{Variables}

\subsubsection{Dependent Variable}

Different from other studies focusing primarily on individuals' educational attainment, this research focuses on the educational expectation of parents on their children. Parents' educational expectations for their children is regarded as an explained variable in this research to offer a micro-level angle of parental involvement to understand the gender differences in education. As one of the variables of parental involvement, parents' educational expectations show particularly substantial influence on their children's education. As a mediator, parents' educational expectations could influence children's own educational expectations (Bozick et al., 2010; Castro et al., 2015) and influence parents' decisions about their investment of financial resources and emotional company to their children (Liu et al., 2014), thus impacting finally on children's educational achievement and their future socioeconomic status (Campbell, 1983). For the convenience of statistics, the educational expectations are transferred into expected years of education ${ }^{2}$.

\subsubsection{Primary Explanatory Variables}

The priority of this research is to study how gender and different sibling structures influence parents' expectations for their children's education. Therefore, the primary explanatory variables are gender, the number of siblings, and the sibling sex composition. According to the previous research (Zheng, 2013), three variables are chosen to measure the sibling sex composition: whether having brothers (having brothers $=1$ ), whether having sisters (having sisters $=1$ ) and the percentage of girls.

\subsubsection{Controlled Variables}

The main controlled variables of this research are hukou, the family economic status, the highest educational years of parents ${ }^{3}$, the birth order, the academic year, the ethnic group, the occupational status of father ${ }^{4}$, parents' comments on their child's current academic achievement and the standardized score of cognitive ability test.

\footnotetext{
${ }^{2}$ CEPS has divided parents' educational level into ten levels. 'Stop education now' is replaced by 8 or 9 years according to children's grade, 'secondary school' by 9 years, 'high school', 'vocational high school' and 'polytechnic school/technical school' by 12 years as these three levels of education are considered as of the similar value in China, 'junior college' as 15 tears, 'Bachelor's degree' as 16 years, 'Master's degree' as 19 years and 'Philosophy of Doctor' as 21 years.

3 CEPS has divided parents' educational level into nine levels. The educational level is replaced by calculating the corresponding years of education to make our statistics more explainable. Following the experience of previous study (Wu, 2012; Zheng, 2013), 'receiving no education' is replaced by 0 year, 'primary school' by 6 years, 'secondary school' by 9 years, 'high school', 'vocational high school' and 'polytechnic school/technical school' by 12 years as these three levels of education are considered as of the similar value in China, 'junior college' as 15 tears, 'undergraduate education' as 16 years and 'graduate education' as 19 years.

${ }^{4}$ CEPS divides the occupation of father into 10 categories, which are simplified in this study into two categories in our research drawing on the experience of the previous research (Liu et al., 2014): the higher occupational
} 
Table 1 shows the descriptive information on all the variables in this study. The mean of parents' expected years for education of their children is 15.93 years, nearly the duration for completing undergraduate education in China (16 years). Girls account for only $48.69 \%$ of the sample, while boys account for $51.31 \%$. This uneven proportion might indicate some families' preference for boys to some extent in terms of giving birth (Cui \& Song, 2019). There is no large distance in the percentage of having brothers $(31.40 \%)$ and having sisters $(32.91 \%)$. In terms of hukou, over a half of the children in the sample $(54.44 \%)$ have a rural hukou. This means that the rural population still takes up a major part in China. Most families report their family economic status as medium $(73.30 \%)$, and just a few think that they are very poor $(3.68 \%)$ or very rich $(0.31 \%)$. The mean of the highest educational level of parents is 10.85 years, corresponding with the time for almost finishing the second year of high school in China, and its standard deviation is 3.11. This indicates that the general educational level of the generation of these children's parents is not very high, and this might be attributed to the insufficient educational resources in China when their parents were young. The mean of the number of siblings is very small (0.74), because there are many one-child families in China. Most children (71.23\%) in their families are ranked the oldest, because of a large number of the single child in many one-child families. The Grade Seven students take up over the half of the children $(52.52 \%)$. Regarding the ethnic group, Han still accounts for a very large proportion of all the sample (91.6\%). Most children's father works in the manufacture, business and service industries, the individual householder, the farmer and the unemployed (81.27\%), and these occupations are counted as the lower level of occupational status in this study. Most parents consider their child's current academic achievement as middle (34.58\%), and the parents giving a positive feedback of their child's academic achievement $(30.76 \%+6.62 \%=37.38 \%)$ outnumber those giving a negative one $(8.56 \%+19.49 \%=28.05 \%)$.

Table 1.

Description of Variables

\begin{tabular}{|c|c|c|}
\hline & Mean/Percentage (\%) & Notes \\
\hline Parents' educational expectation & 15.93 & Standard deviation 2.86 \\
\hline \multicolumn{3}{|l|}{ Gender } \\
\hline Male & 51.31 & Male $=0$, female $=1$ \\
\hline Female & 48.69 & \\
\hline \multicolumn{3}{|l|}{ Whether having brothers } \\
\hline Having brothers & 31.40 & $\begin{array}{l}\text { Having no brother }=0 \text {, } \\
\text { having brothers }=1\end{array}$ \\
\hline Having no brother & 68.60 & \\
\hline \multicolumn{3}{|l|}{ Whether having sisters } \\
\hline Having sisters & 32.91 & $\begin{array}{l}\text { Having no sister }=0 \text {, } \\
\text { having sisters }=1\end{array}$ \\
\hline Having no sister & 67.09 & \\
\hline Percentage of girls & 0.29 & Standard deviation 0.25 \\
\hline \multicolumn{3}{|l|}{ Hukou } \\
\hline Urban & 45.56 & Urban $=0$, rural $=1$ \\
\hline Rural & 54.44 & \\
\hline \multicolumn{3}{|l|}{ Family economic status } \\
\hline Very poor & 3.68 & \\
\hline Comparatively poor & 16.97 & \\
\hline Medium & 73.30 & \\
\hline Comparatively rich & 5.74 & \\
\hline Very rich & 0.31 & \\
\hline $\begin{array}{l}\text { The highest educational level of } \\
\text { parents }\end{array}$ & 10.85 & Standard deviation 3.11 \\
\hline
\end{tabular}

category includes the leader and employee in the government or the state-owned organizations, the manager in the enterprises, the teacher, engineer, the doctor and the lawyer and the lower category includes the technical worker(including driver), the employee in the manufacture, business and service industries, the individual householder, the farmer and the unemployed. 


\begin{tabular}{|c|c|c|}
\hline Number of siblings & 0.74 & Standard deviation 0.86 \\
\hline \multicolumn{3}{|l|}{ Birth order } \\
\hline Ranked as the oldest & 71.23 & \\
\hline Ranked in the middle & 5.28 & \\
\hline Ranked as the youngest & 23.49 & \\
\hline \multicolumn{3}{|l|}{ Academic year } \\
\hline Grade Seven & 52.52 & $\begin{array}{l}\text { Grade Seven }=0, \quad \text { Grade } \\
\text { Nine }=1\end{array}$ \\
\hline Grade Nine & 47.48 & \\
\hline \multicolumn{3}{|l|}{ Ethnic group } \\
\hline Han & 91.60 & $\operatorname{Han}=0$, non-Han $=1$ \\
\hline Non-Han & 8.40 & \\
\hline \multicolumn{3}{|l|}{ Profession of father } \\
\hline $\begin{array}{l}\text { Father works in the manufacture, } \\
\text { business and service industries, the } \\
\text { individual householder, the farmer and } \\
\text { the unemployed }\end{array}$ & 81.27 & $\begin{array}{l}\text { Father works in the } \\
\text { manufacture, business and } \\
\text { service industries, the } \\
\text { individual householder, the }\end{array}$ \\
\hline $\begin{array}{l}\text { Father works as leader or staff in } \\
\text { state-owned institutions/in the } \\
\text { management layer of enterprises/as } \\
\text { intellectual employees }\end{array}$ & 18.73 & $\begin{array}{l}\text { farmer and the } \\
\text { unemployed=0, Father } \\
\text { works as leader or staff in } \\
\text { state-owned institutions/in } \\
\text { the management layer of } \\
\text { enterprises/as intellectual } \\
\text { employees =1 }\end{array}$ \\
\hline \multicolumn{3}{|l|}{$\begin{array}{l}\text { Parents' comments on their child's } \\
\text { current academic achievement }\end{array}$} \\
\hline Very bad & 8.56 & \\
\hline Comparatively bad & 19.49 & \\
\hline Middle & 34.58 & \\
\hline Comparatively good & 30.76 & \\
\hline Very good & 6.62 & \\
\hline $\begin{array}{l}\text { Standardized score of cognitive ability } \\
\text { test }\end{array}$ & 0.02 & Standard deviation 0.86 \\
\hline
\end{tabular}

\subsection{Analytical Strategy}

From the methodological perspective, this study contains three steps:

The first part uses the statistical package STATA to determine the ordinary least squares (OLS) regression for coefficients of gender, number of siblings, sibling sex composition and other controlled variables on the parents' educational expectations.

The second part is to determine the OLS regression for coefficients of gender on the parents' educational expectations in two different groups: one-child families and multiple-children families.

The regression model to determine the effect of gender and number of siblings on parents' educational expectations stands as follows:

$$
P=\beta_{0}+\beta_{1} \text { Gender }+\beta_{2} \text { Number of siblings }+\sum \beta_{3} X+\varepsilon
$$

The regression model to determine the effect of sibling sex composition on parents' educational expectations stands as follows:

$$
\begin{gathered}
P=\beta_{0}+\beta_{1} \text { Sibling sex composition }+\beta_{2} \text { Gender }+\beta_{3} \text { Number of siblings }+ \\
\sum \beta_{4} X+\varepsilon
\end{gathered}
$$

The third part analyses how gender interacts with the other controlled variables. Taking the interaction of gender and hukou as an example, the regression model with interactions stands as follows:

$$
P=\beta_{0}+\beta_{1} \text { Gender }+\beta_{2} \text { Hukou }+\beta_{3} \text { Gender } * \text { Hukou }+\sum \beta_{4} X+\varepsilon
$$

$P$ refers to the parents' expected years of education for their children.

$\mathrm{X}=$ Controlled variables $\{h u k o u$, family economics status, etc. $\}$ 
This study also tests and confirms the existence of the heteroskedasticity in the OLS regression, and it is accounted for by the robust standard errors.

\section{Results}

4.1.Gender, sibling compositions, and parents' educational expectations

The first model in Table 2 shows differences from some previous research that is parents have 0.195 more years of educational expectations on girls than boys $(\mathrm{P} \leq 0.001)$. Therefore, the first hypothesis of this study has been proved false. As expected, the residential areas, the educational level of parents, the father's professional status, academic achievement, and cognitive ability have a significantly positive relationship with parents' educational expectations. However, family economic status, which means household incomes, has no significant impact on gender differences in parents' educational expectations. Although it is different from the expectation, this find is still reasonable in the cultural context of China. Goyette and Xie (1999) indicated that Asian parents might still spend a large proportion of their family incomes to support their offspring's education, because education is attached to great value in Asian cultures. Some other Chinese scholars found that parents from low-income families try everything to support their children's education because they believe that good education could help their children to get rid of poverty in the future (Xu \& Zhou, 2017; Xiong, 2017).

Table 2.

Gender, number of siblings and parents' educational expectation

\begin{tabular}{|c|c|c|}
\hline & Model 1 & Model 2 \\
\hline Female & $\begin{array}{c}0.195^{* * *} \\
(4.99)\end{array}$ & $\begin{array}{c}0.149^{* * *} \\
(2.95)\end{array}$ \\
\hline Rural residential areas & $\begin{array}{l}-0.111^{*} \\
(-2.43)\end{array}$ & $\begin{array}{l}-0.114^{*} \\
(-2.48)\end{array}$ \\
\hline \multicolumn{3}{|l|}{ Family economic status } \\
\hline Comparatively poor & $\begin{array}{c}0.0724 \\
(0.57)\end{array}$ & $\begin{array}{c}0.0699 \\
(0.55)\end{array}$ \\
\hline Medium & $\begin{array}{c}-0.0492 \\
(-0.41)\end{array}$ & $\begin{array}{c}-0.0511 \\
(-0.43)\end{array}$ \\
\hline Comparatively rich & $\begin{array}{c}0.0447 \\
(0.32)\end{array}$ & $\begin{array}{c}0.0429 \\
(0.30)\end{array}$ \\
\hline Very rich & $\begin{array}{l}0.460 \\
(1.02)\end{array}$ & $\begin{array}{l}0.456 \\
(1.01)\end{array}$ \\
\hline Highest educational years of parents & $\begin{array}{c}0.151^{\text {**** }} \\
(17.77)\end{array}$ & $\begin{array}{c}0.152^{* * * *} \\
(17.79)\end{array}$ \\
\hline Number of siblings & $\begin{array}{c}-0.107^{* * *} \\
(-3.11)\end{array}$ & $\begin{array}{c}-0.136^{* *} \\
(-3.25)\end{array}$ \\
\hline \multicolumn{3}{|l|}{ Birth order } \\
\hline Ranked in the middle & $\begin{array}{c}-0.0869 \\
(-0.74)\end{array}$ & $\begin{array}{l}-0.101 \\
(-0.86)\end{array}$ \\
\hline Ranked as the youngest & $\begin{array}{l}0.100 \\
(1.84)\end{array}$ & $\begin{array}{l}0.108^{*} \\
(1.98)\end{array}$ \\
\hline Grade 9 & $\begin{array}{c}-0.681^{* * * *} \\
(-17.91)\end{array}$ & $\begin{array}{c}-0.682^{* * * *} \\
(-17.93)\end{array}$ \\
\hline Minor ethnic groups & $\begin{array}{c}0.301^{\text {**** }} \\
(4.22)\end{array}$ & $\begin{array}{c}0.300^{* * * *} \\
(4.21)\end{array}$ \\
\hline $\begin{array}{l}\text { Father works as leader or staff in state-owned } \\
\text { institutions/in the management layer of } \\
\text { enterprises/as intellectual employees }\end{array}$ & $0.373^{* * * *}$ & $0.374^{* * *}$ \\
\hline $\begin{array}{l}\text { Parents' comments on their child's current } \\
\text { academic achievement }\end{array}$ & $(6.61)$ & $(6.62)$ \\
\hline Comparatively bad & $\begin{array}{c}0.699^{* * * *} \\
(7.85)\end{array}$ & $\begin{array}{c}0.701^{* * * *} \\
(7.86)\end{array}$ \\
\hline Middle & $\begin{array}{c}1.602^{* * * *} \\
(19.06)\end{array}$ & $\begin{array}{l}1.603^{* * *} \\
(19.06)\end{array}$ \\
\hline Comparatively good & $2.487^{* * *}$ & $2.487^{* * *}$ \\
\hline
\end{tabular}




\begin{tabular}{lcc}
\hline \multirow{2}{*}{ Very good } & $(29.06)$ & $(29.06)$ \\
& $3.170^{* * *}$ & $3.171^{* * *}$ \\
Standardized score of cognitive ability test & $(29.59)$ & $(29.59)$ \\
& $0.382^{* * *}$ & $0.383^{* * *}$ \\
Female $*$ Number of siblings & $(15.21)$ & $(15.23)$ \\
& & 0.0636 \\
${ }_{\text {ccons }}$ & $12.90^{* * *}$ & $(1.27)$ \\
$N$ & $(73.98)$ & $(74.02)$ \\
\hline$t$ statistics in parentheses & 17216 & 17216 \\
${ }^{*} p<0.05,{ }^{* *} p<0.01,{ }^{* * *} p<0.001$ & &
\end{tabular}

The number of siblings in Model 1 has a significantly negative influence on parents' educational expectations $(\mathrm{P} \leqslant 0.01)$. This indicates that the dilution model exists as parents have to expect on each child if there are more children to share the limited educational resources. However, in Model 2, the coefficient of the interaction of gender and number of siblings is not statistically significant, and this means that there is no significant difference in the negative impact of a larger family size for boys or girls. This finding is different from the previous studies on this topic. Therefore, the fourth hypothesis is partially confirmed because the number of siblings is proved to have a negative impact on parents' educational expectations, but this negative impact shows no significant gender differences.

Table 3 shows the gender differences in parents' educational expectations in one-child families and multiple-children families. In consistent with Liu's research (2014), the 'only girl' receive more educational expectations than the 'only boy'. As can be seen in Model 3, the 'only girl' receives 0.093 more years of education than boys in the same family structure $(\mathrm{P} \leq 0.05)$. Surprisingly, girls' advantage in receiving higher parents' educational expectations remains in multiple-children families, and girls even have 0.262 more years of educational expectations than boys when they have siblings $(\mathrm{P} \leq 0.001)$. Therefore, the first part of the second hypothesis is confirmed, because in the one-child families, parents have higher educational expectations for girls than boys. However, the second part of this hypothesis is not proved true, as in multiple-children families, parents still expect girls to receive more education than boys, and even this preference for girls to have more education is more significant in multiple-children families than in the one-child families. This finding might be attributed to the decline of traditional patriarchal beliefs and the progress of modernization in China (Wu, 2012).

Table 3.

Comparison between the one-child families and multiple-children families

\begin{tabular}{lcc}
\hline & Model 3 & Model 4 \\
\hline Female & $0.0927^{* *}$ & $0.262^{* * * *}$ \\
Rural residential areas & $(1.70)$ & $(4.68)$ \\
& $-0.294^{* * *}$ & 0.0261 \\
Family economic status & $(-4.35)$ & $(0.41)$ \\
Comparatively poor & & \\
& -0.0248 & 0.0855 \\
Medium & $(-0.09)$ & $(0.60)$ \\
Comparatively rich & -0.138 & -0.0374 \\
& $(-0.52)$ & $(-0.28)$ \\
Very rich & -0.0875 & 0.140 \\
Highest educational years of parents & $(-0.31)$ & $(0.79)$ \\
& 0.0683 & 0.723 \\
Number of siblings & $(0.11)$ & $(1.09)$ \\
Birth order & $0.174^{* * *}$ & $0.126^{* * *}$ \\
Ranked in the middle & $(14.83)$ & $(10.20)$ \\
& & $-0.112^{*}$ \\
& & $(-2.20)$ \\
\end{tabular}




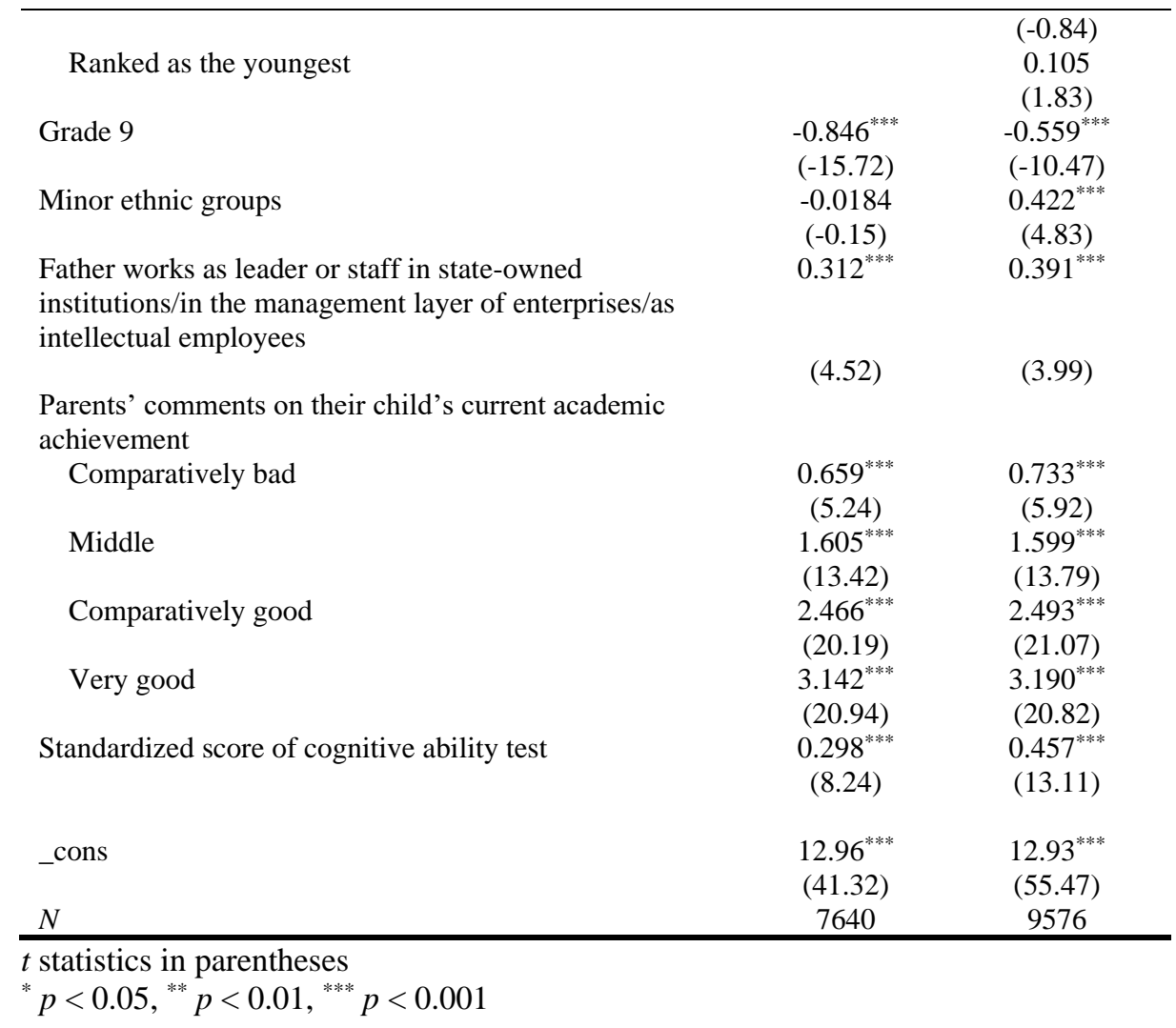

Model 5 to Model 7 in Table 4 shows the impact of sibling sex compositions on parents' expectations attached on their children's education. Although the results show that having any brother is negative for children to have more educational expectations from their parents, and having any sister or having more girls in the family is helpful to receive more parents' educational expectations, all the results are not statistically significant. The third hypothesis has been proved false. In this study, different sibling sex compositions have no significant influence on the educational expectations from parents.

Table 4.

Sibling sex composition and parents' educational expectations

\begin{tabular}{llll}
\hline Female & Model 5 & Model 6 & Model 7 \\
Having any brother & $0.274^{* * * *}$ & $0.270^{* * *}$ & $0.273^{* * * *}$ \\
& $(4.77)$ & $(4.76)$ & \\
Having any sister & -0.0565 & & \\
& $(-0.97)$ & 0.0535 & \\
Percent of girls & & $(0.92)$ & 0.117 \\
& & & $(1.01)$ \\
Rural residential areas & & 0.0242 \\
Family economic status & 0.0250 & 0.0246 & $(0.38)$ \\
Comparatively poor & $(0.40)$ & $(0.39)$ & 0.0843 \\
& & & $(0.60)$ \\
Medium & 0.0843 & 0.0849 & -0.0393 \\
Comparatively rich & $(0.60)$ & $(0.60)$ & $(-0.29)$ \\
Very rich & -0.0398 & -0.0383 & 0.137 \\
Highest educational years of parents & $(-0.30)$ & $(-0.29)$ & $(0.77)$ \\
& 0.136 & 0.137 & 0.718 \\
Number of siblings & $(0.77)$ & $(0.78)$ & $(1.09)$ \\
& 0.718 & 0.719 & $0.126^{* * *}$ \\
& $(1.09)$ & $(1.09)$ & $(10.18)$ \\
& $0.126^{* * *}$ & $0.126^{* * *}$ & $-0.122^{*}$
\end{tabular}




\begin{tabular}{|c|c|c|c|}
\hline & $(-2.07)$ & $(-2.33)$ & $(-2.36)$ \\
\hline \multicolumn{4}{|l|}{ Birth order } \\
\hline Ranked in the middle & $\begin{array}{l}-0.1000 \\
(-0.82)\end{array}$ & $\begin{array}{l}-0.114 \\
(-0.94)\end{array}$ & $\begin{array}{l}-0.108 \\
(-0.89)\end{array}$ \\
\hline Ranked as the youngest & $\begin{array}{l}0.0922 \\
(1.56)\end{array}$ & $\begin{array}{l}0.0945 \\
(1.61)\end{array}$ & $\begin{array}{l}0.0921 \\
(1.56)\end{array}$ \\
\hline Grade 9 & $\begin{array}{l}-0.561^{* * *} \\
(-10.48)\end{array}$ & $\begin{array}{l}-0.561^{* * *} \\
(-10.48)\end{array}$ & $\begin{array}{l}-0.561^{* * *} \\
(-10.49)\end{array}$ \\
\hline Minor ethnic groups & $\begin{array}{l}0.427^{* * * *} \\
(4.88)\end{array}$ & $\begin{array}{l}0.425^{* * *} \\
(4.86)\end{array}$ & $\begin{array}{l}0.426^{* * * *} \\
(4.87)\end{array}$ \\
\hline $\begin{array}{l}\text { Father works as leader or staff in state-owned } \\
\text { institutions/in the management layer of enterprises/as } \\
\text { intellectual employees }\end{array}$ & $0.393^{* * *}$ & $0.393^{* * *}$ & $0.393^{* * * *}$ \\
\hline \multicolumn{4}{|l|}{$\begin{array}{l}\text { Parents' comments on their child's current academic } \\
\text { achievement }\end{array}$} \\
\hline Comparatively bad & $\begin{array}{l}0.393^{* * *} \\
(4.01)\end{array}$ & $\begin{array}{l}0.393^{* * *} \\
(4.01)\end{array}$ & $\begin{array}{l}0.393^{* * * *} \\
(4.01)\end{array}$ \\
\hline Middle & $\begin{array}{l}0.393^{* * * *} \\
(4.01)\end{array}$ & $\begin{array}{l}0.393^{* * *} \\
(4.01)\end{array}$ & $\begin{array}{l}0.393^{* * *} \\
(4.01)\end{array}$ \\
\hline Comparatively good & $\begin{array}{l}0.393^{* * * *} \\
(4.01)\end{array}$ & $\begin{array}{l}0.393^{* * *} \\
(4.01)\end{array}$ & $\begin{array}{l}0.393^{* * * *} \\
(4.01)\end{array}$ \\
\hline Very good & $\begin{array}{l}0.393^{* * *} \\
(4.01)\end{array}$ & $\begin{array}{l}0.393^{* * *} \\
(4.01)\end{array}$ & $\begin{array}{l}0.393^{* * * *} \\
(4.01)\end{array}$ \\
\hline Standardized score of cognitive ability test & $\begin{array}{l}0.455^{* * *} \\
(13.08)\end{array}$ & $\begin{array}{l}0.456^{* * *} \\
(13.09)\end{array}$ & $\begin{array}{l}0.456^{\text {**** }} \\
(13.09)\end{array}$ \\
\hline _cons & $\begin{array}{l}12.96^{* * * *} \\
(55.40)\end{array}$ & $\begin{array}{l}12.92^{* * * *} \\
(55.32)\end{array}$ & $\begin{array}{l}12.92^{* * * *} \\
(55.30)\end{array}$ \\
\hline$N$ & 9576 & 9576 & 9576 \\
\hline
\end{tabular}

$t$ statistics in parentheses

${ }^{*} p<0.05,{ }^{* *} p<0.01,{ }^{* * *} p<0.001$

\subsection{The interactive effect of gender and other variables of family background}

Model 8 in Table 5 shows that there exist gender differences in how the hukou influences parents' expectations for children's education. Living in rural areas makes boys lose 0.206 years of expectations from their parents $(\mathrm{P} \leq 0.001)$ than those in urban arears. However, the positive coefficient of the interaction of gender and residential areas shows that the adverse effects of living in rural areas are less negative to girls than to boys $(\mathrm{P} \leq 0.05)$. Therefore, there does exist gender differences in the effect of hukou on parents' educational expectations. However, surprisingly, girls in rural areas seem not to be influenced by 'the preference for boys'.

Table 5.

The Interactive Effects of Gender and Other Variables of Family Background

\begin{tabular}{lccc}
\hline \hline & Model 8 & Model 9 & Model 10 \\
\hline Female & $0.0907^{*}$ & $0.591^{* * *}$ & $0.276^{* * *}$ \\
Rural residential areas & $(1.65)$ & $(4.05)$ & $(6.31)$ \\
& $-0.206^{* * *}$ & $-0.113^{*}$ & $-0.110^{*}$ \\
Family economic status & $(-3.35)$ & $(-2.46)$ & $(-2.41)$ \\
Comparatively poor & & & \\
& 0.0738 & 0.0768 & 0.0759 \\
Medium & $(0.58)$ & $(0.61)$ & $(0.60)$ \\
& -0.0477 & -0.0462 & -0.0497 \\
Comparatively rich & $(-0.40)$ & $(-0.39)$ & $(-0.42)$ \\
& 0.0496 & 0.0484 & 0.0447 \\
Very rich & $(0.35)$ & $(0.34)$ & $(0.32)$ \\
& 0.443 & 0.462 & 0.463 \\
Highest educational years of parents & $(0.98)$ & $(1.02)$ & $(1.03)$
\end{tabular}




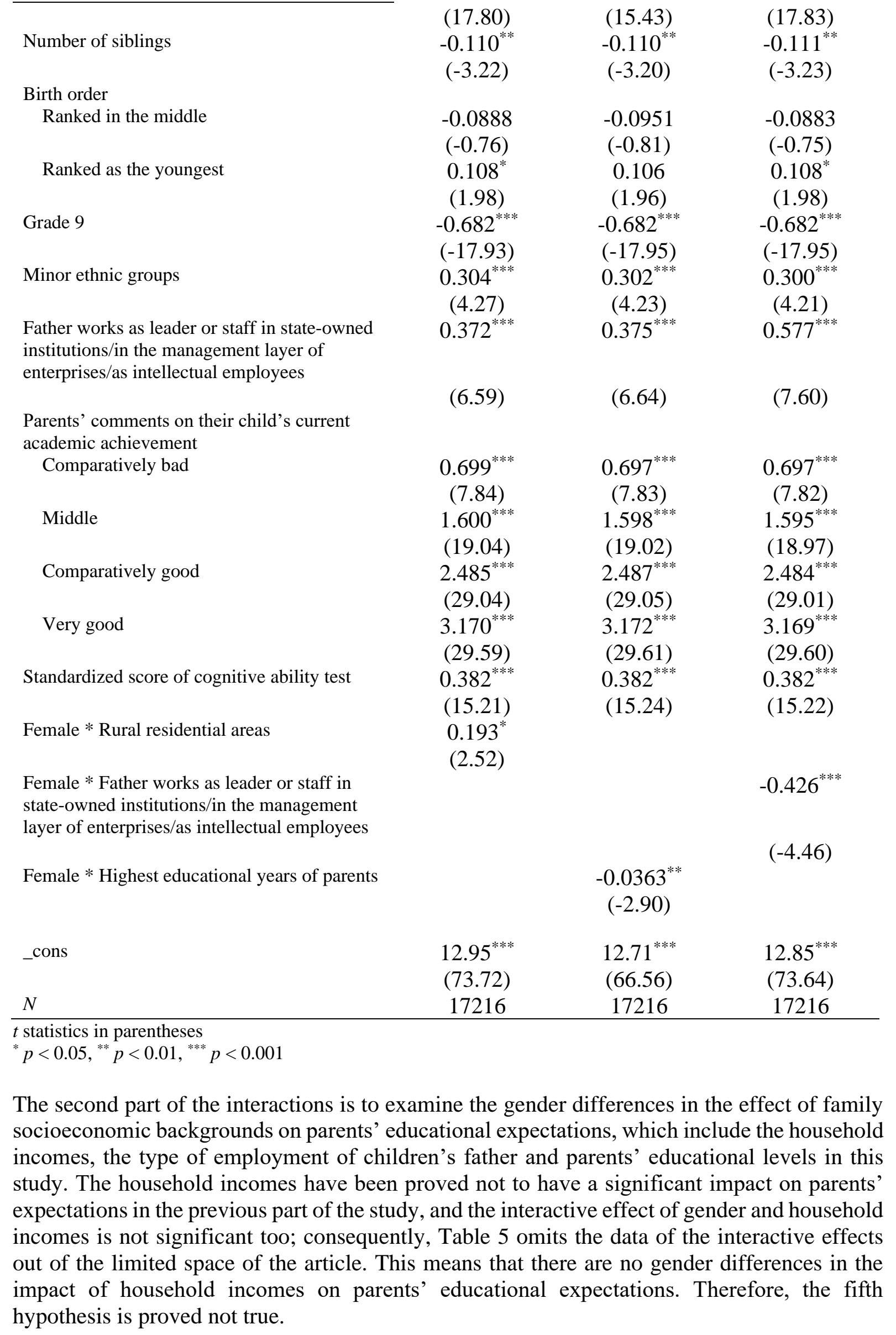


Model 9 shows the interaction of gender and the parents' educational years. With the rise of parents' educational level, the gender gap in parents' expectations for children's education is narrowing, because boys, who generally receive fewer educational expectations from their parents, benefit more than girls when their parents receive more education $(\mathrm{P} \leq 0.01)$. The sixth hypothesis can be confirmed. The gender-egalitarian perspective might be able to explain the observation. Parents of higher levels of education tend to expect more on boys based on the fact that boys are sometimes more vulnerable in the educational system.

Model 10 shows the interactive effect of gender and father's employment type. The main effect of gender is positive, but the interaction of gender and father's employment type is negative and significant $(\mathrm{P} \leq 0.001)$. This means that father's higher socioeconomic occupation on the contrary weakens girls' advantage in parents' educational expectations (when girls' father has a higher socioeconomic level of occupation, they receive $0.276-0.426=0.15$ less years of educational expectations than boys in the same situation). Therefore, the seventh hypothesis can be confirmed.

\section{Discussion and Conclusion}

This research provides a new perspective of parents' expectations for their children's education and gender inequality in education, compared with other studies that tried to understand why girls outperform boys through the biological differences and educational system (Gold, 1982; Gurian \& Stevens, 2005; Kleinfeld, 2009; Sommers, 2013). This study shows that parents generally expected girls to have more education, even in families with more than one child. Besides, a larger family size generally has a negative impact on parents' educational expectations for their children, but there are no gender differences in this negative impact. Finally, sibling sex composition shows no significant impact on parents' educational expectations.

Gender differences in different family backgrounds on parents' expectations for children's education do exist. The results show that a better family background, such as living in urban areas, parents' higher educational levels and a higher socioeconomic level of father's occupation, can narrow the gender gap in parents' educational expectations.

Finally, there exist some limitations of this research. First, in this study, the primary finding, which means that Chinese parents hope girls to receive more education than boys, is different from most previous studies. This might be because some variables are not mutually exclusive in the OLS regression model. For example, the previous literature (Black et al., 2005) suggested that there might exist endogenous problems in terms of the causal relation between the family size and children's educational attainment. More specifically, a larger family size might not have the causal effect on children's educational attainment. Instead, it might be because the families who choose to have more children are inherently different, and their children will have lower education regardless of the family size. Black (2005) used twins as an instrumental variable for family size to try to solve the endogenous problems. This study considers that the future studies could perhaps also use twins, even boy-girl twins as an instrumental variable for family size to further examine the gender differences in parents' educational expectations in multiple-children families. Also, more studies might need to be done to explore the reasons behind the conflict results on gender differences in parents' expectations for children's education attainment. Second, this study suggests that parents generally have higher educational expectations for girls than boys might because of the higher rate of return to education for girls. However, this causal relation still needs to be verified in the future studies. Additionally, some research suggests that it may be because girls are more willing to interact with their parents than boys, which leads parents to involve more into girls' education (Zhou \& Cheng, 2016). Overall, future research may try to have consistent results of gender differences in parents' educational expectations, and delve into the reasons behind their findings. 


\section{Reference}

Becker, G. S., \& Tomes, N. (1979). An equilibrium theory of the distribution of income and intergenerational mobility. Journal of Political Economy, 87(6), 1153-1189.

Black, S. E., Devereux, P. J. \& Salvanes, K. G. (2005). The More the Merrier? The Effect of Family Size and Birth Order on Children's Education. Quarterly Journal of Economics, 120(2), 669-700.

Blau, P. M. \& Duncan, O.D. (1967). The American Occupation Structure. New York: John Wiley.

Blake, J. (1981). Family size and the quality of children. Demography, 18(4), 421-442.

Boss Zhipin. (2019). Research on Gender Differences in China's Job Market. Retrieved from: https://doc.mbalib.com/view/c32ecbb3f5a9259eb6dcee8bb13d46e8.html.

Buchmann, C., DiPrete, T.A. \& McDaniel, A. (2008). Gender Inequalities in Education. Annual Review of Sociology, 34(1), 319-337.

Buchmann, C., \& DiPrete, T.A. (2006). The growing female advantage in college completion. The role of family background and academic achievement. American Sociological Review, 71(4), 515-541.

Bozick, R., Alexander, K., Entwisle, D., \& Kerr, D. K. (2010). Framing the future: revisiting the place of educational expectations in status attainment. Social Forces, 88(5), 2027-2052.

Castro, M., E. Expósito-Casas, López-Martín, E., Lizasoain, L., Navarro-Asencio, E. \& Gaviria, J. L. (2015). Parental involvement on student academic achievement: a metaanalysis. Educational Research Review, 14, 33-46.

Campbell, R. T. (1983). Status attainment research: end of the beginning or beginning of the end? Sociology of Education, 56(1), 47-62.

Cherlin, A. \& Walters P. B. (1981). Trends in United States Men's and Women's Sex-Role Attitudes: 1972-1978. American Sociological Review, 46(4), 453-60.

Cherng, H. Y. S., \& Hannum, E. (2013). Community poverty, industrialization, and educational gender gaps in rural China. Social Forces, 92(2), 659-690.

Cui, S. \& Song F.-fang. (2019). Gender Differences in Parental Educational Expectations and Input: Empirical Research based on the Chinese Educational Panel Survey. Renmin University of China Educational Journal, (2), 154-166.

Douglas, J. W. B. (1964). The home and the school: A study of ability and attainment in the primary school. London: McGibbon \& Kee.

Fry, R. \& Cohn, D. (2010). Women, Men and the New Economics of Marriage. Pew Research Center. Retrieved from: https://www.pewresearch.org/wpcontent/uploads/sites/3/2010/11/new-economics-of-marriage.pdf.

Gold, D. (1982). Male teacher effects on young children: A theoretical and empirical consideration. Sex Roles, 8(5), 493-513.

Goldin, C., Katz L. F. \& Kuziemko I. (2006). The Homecoming of American College Women: The Reversal of The College Gender Gap. Journal of Economic Perspectives, 20(4), 133 156.

Goyette, K. \& Xie, Y. (1999). Educational Expectations of Asian American Youths: Determinants and Ethnic Differences. Sociology of Education, 72(1), 22-36. 
Gudrun, Q. \& Hurrelmann, K. (2013) The growing gender gap in education. International Journal of Adolescence and Youth, 18(2), 69-84.

Gurian, M. \& Stevens K. (2005). The Minds of Boys: Saving Our Sons from Falling Behind in School and Life. San Francisco: Jossey-Bass.

Hannum, E. (2005). Market transition, educational disparities, and family strategies in rural China: new evidence on gender stratification and development. Demography, 42(2), 275299.

Hannum, E., Kong, P., \& Zhang, Y. (2009). Family sources of educational gender inequality in rural China: a critical assessment. International Journal of Educational Development, 29(5), 474-486.

Hauser, R. M., \& Kuo, H. H. D. (1998). Does the gender composition of sibships affect women's educational attainment? Journal of Human Resources, 33(3), 644-657.

Jacob, M. (2011). Do brothers affect their sisters' chances to graduate? An analysis of sibling sex composition effects on graduation from a university or a Fachhochschule in Germany. Higher Education, 61(3), 277-291.

Ji, Y.-chun. (2017). A Mosaic Temporality: New Dynamics of the Gender and Marriage System in Contemporary Urban China. Temporalités, 26, 1-19. URL: http://journals.openedition.org/temporalites/3773.

Kaestner, R. (1997). Are brothers really better? Sibling sex composition and educational achievement revisited. Journal of Human Resources, 32(2), 250-2.

Kleinfeld, J. (2009). No Map to Manhood: Male and Female Mindsets Behind the College Gender Gap. Gender Issues, 26(3), 171-182.

Lavely, W., Xiao, Z., Li, B. \& Freedman, R. (1990). The Rise in Female Education in China: National and Regional Patterns. The China Quarterly, 121, 61-93.

Laslett, P. (1991). A fresh map of life: the emergence of the third age. Cambridge: Harvard University Press.

Legewie, J., \& DiPrete, T.A. (2009). Family determinants of the changing gender gap in educational attainment. A comparison of the U.S. and Germany. Schmollers Jahrbuch, 129, 169-180.

Li, C.-ling. (2009). Gender Differences in Educational Attainment: Impacts of Family Background on Educational Attainment of Men and Women. Collection of Women's Studies, 90, 14-18.

Li, C.-ling. (2010). Expansion of Higher Education and Inequality in Opportunity of Education: A study on effect of "Kuozhao" policy on equalization of educational attainment. Sociological Studies, (3), 82-110.

Li, C.-ling. (2016). "Boy Crisis", "Leftover Women" and "Employment Discrimination against Female College Graduates": Challenges of Reversed Gender Disparity in Education. Collection of Women's Studies, 134, 33-38.

Li, D., \& Tsang, M. C. (2003). Household decisions and gender inequality in education in rural China. China an International Journal, 1(2), 224-248.

Li, J.-hong \& Lavely, W. (2003). Village Context, Women's Status, and Son Preference Among Rural Chinese Women. Rural Sociology, 68(1), 87-106. 
Liu, B.-zhong, Zhang, Y.-yun, Li, J.-xin. (2014). Socioeconomic Status, Cultural Idea and Family Educational Expectation. Youth Studies (6), 46-53.

Liu, Y.-shan \& Wang, Z.-ming. (2008). Women enter the elite group: limited progress. Journal of Higher Education, 29, 49-61.

Luo, K., \& Zhou, L. (2010). Effects of birth order and gender differences on educational human capital: an analysis based on family economics. Economic Science, 32(3), 107-119.

Murphy, R., Tao, R., \& Lu, X. (2011). Son preference in rural china: patrilineal families and socioeconomic change. Population and Development Review, 37(4), 665-690.

Neuenschwander, M. P., Vida, M., Garrett, J. L., \& Eccles, J. S. (2007). Parents' expectations and students' achievement in two western nations. International Journal of Behavioral Development, 31(6), 594-602.

Powell, B. \& Steelman, L. C. (1989). The liability of having brothers - playing for college and the sex composition of the family. Sociology of Education, 62(2), 134-147.

Powell, B., \& Steelman, L. C. (1990). Beyond sibship size: sibling density, sex composition, and educational outcomes. Social Forces, 69, 181-206.

Scharping, T. (2003). Birth control in China 1949-2000: Population policy and demographic development. London: Routledge.

Schwartz, C. R. \& Han, H. (2014). The Reversal of the Gender Gap in Education and Trends in Marital Dissolution. American Sociological Review, 79 (4), 605-629.

Sommers, C. H. (2013). The War Against Boys: How 15Misguided Policies Are Harming Our Young Men. New York: Simon \& Schuster.

Thornton, A., Alwin D. F., \& Camburn D. (1983). Causes and Consequences of Sex-Role Attitudes and Attitude Change. American Sociological Review, 48(2), 211-27.

Wang, X.-tao. (2011). Educational Returns to Urban Full-Time Young Workers: An Analysis of Sex and Only-Child Status. Chinese Journal of Sociology, (4), 158-174.

$\mathrm{Wu}, \mathrm{Y}$.-xiao. (2012). Gender gap in educational attainment in urban and rural China. Society, $32(4), 112-137$.

Xiong, H.-ni. (2017). The Hope of Low-class People for Their Children to Have a Bright Future - Content and Characteristics of Educational Expectations of Working Class Parents. Journal of Research on Education for Ethnic Minorities, 28(5), 105-112.

Xu, S.-jing \& Zhou D.-yang. (2017). A Study on the Mediating Role of Education as the Intergenerational Transmission of Stratum. Social Science, (9), 91-100.

Ye, H. \& Wu X.-gang. (2011). Fertility Decline and the Trend in Educational Gender Inequality in China. Sociological Studies, (5), 153-173.

Zheng, L. (2013). Sibling sex composition, intrafamily resource allocation, and educational attainment: an explanation of educational gender inequality in China. Sociological Studies, (5), 76-103.

Zhou, F. \& Cheng T.-jun. (2016). Gender Differences in Secondary School Students' Educational Expectations: Analysis of the Impact of Parental Involvement. Educational Research and Experiment, (6), 7-16. 